\title{
On the excavation-induced stress drop in damaged coal considering a coupled yield and failure criterion
}

\author{
Dongjie Xue ${ }^{1,2,3}$ (I) Jie Zhou ${ }^{1} \cdot$ Yintong Liu $^{1} \cdot$ Lie Gao $^{1}$
}

Received: 10 April 2019/Revised: 21 September 2019/Accepted: 10 January 2020/Published online: 31 January 2020

(C) The Author(s) 2020

\begin{abstract}
Investigating the stress drop of abutment pressure is the key to a deep quantitative analysis of the discontinuous stress redistribution under mining. In the present study, uniaxial and triaxial compression tests are carried out separately to determine the bulk and shear moduli, the cohesion, and the internal friction angle of the coal samples. By extending the meaning of Mohr's circle referring to yield stress instead of the maximum principal stress, a yield line is introduced to illustrate the stress drop of Mohr's circle referring to yield stress instead of the maximum principal stress at the elastoplastic boundary. Furthermore, a theoretical solution of the stress drop as a function of the damage is proposed to investigate how the abutment pressure differs considering the yield line and failure line. In addition, applying the stress drop at the yield line in non-pillar mining, top coal mining, and protective coal mining shows that the damage has a nonlinearly positive influence on the stress drop. The results shows that the bulk modulus and internal friction angle have a more sensitive influence on the stress drop than do the shear modulus and cohesion. Finally, the stress drop is divided into a discontinuous stress drop at the yield line and a structural stress drop at the failure line. The stress drop is effective in describing the discontinuous stress redistribution and shows a clear difference in the movement direction of Mohr's circle considering the unloading pressure.
\end{abstract}

Keywords Stress drop · Abutment pressure · Mohr's circle $\cdot$ Yield line $\cdot$ Failure line

\section{Introduction}

Coal mining or other rock excavation often causes stress redistribution, which is a pressure-released process with a drop in stress (Xu et al. 2014; Poeck et al. 2016). Many contributions to continuous abutment pressure are made with increasing confining pressure. Under conventional

Dongjie Xue

xuedongjie@163.com

1 School of Mechanics and Civil Engineering, China University of Mining and Technology, Beijing 100083, China

2 State Key Laboratory of Coal Mine Disaster Dynamics and Control, Chongqing University, Chongqing 400030, China

3 Key Laboratory of Safety and High-Efficiency Coal Mining, Anhui University of Science and Technology, Huainan 232001, China triaxial compression (CTC), the coal often becomes ductile only with a stress drop at failure (Byerlee 1968; Simpson 1985; Evans et al. 1990; Wong and Baud 2012). Indeed, the accumulated plasticity also has an influence on the stress drop, especially for fractured coal (Barton and Zoback 1994). Such results are based on a consideration of increasing stress-dependent behavior without the effects of mining and damage.

For coal, the mining-induced stress changes dramatically with increasing abutment pressure and decreasing confining pressure. There is an obvious pressure-relieved zone around the tunnel, which is seriously damaged by the unloading effect. However, the unloading stress path of the confining pressure is often ignored in a CTC test. For the effect of mining-induced damage (Booth 1986; Spreckels et al. 2001), the coupling result of increasing abutment pressure and decreasing confining pressure shows a 
different stress path. Without considering the mining effect, the stress distribution is always considered as a continuous process with no sudden stress drop. However, coal failure must generate discrete blocks and furthermore a discontinuous stress distribution (Molinda et al. 2008; Qian et al. 2003).

The stress drop has been used extensively to investigate earthquakes (Madariaga 1977) and is also found on a microscopic scale (Allmann and Shearer 2009). Although the stress drop at failure is often observed by a CTC test, to the best of our knowledge there has been little use of the stress drop to investigate the abutment pressure.

For the redistribution of abutment pressure, similar to the stress-strain relationship under triaxial compression, there are two types of transitional behavior at elastoplastic and failure boundaries. The elastoplastic transition refers to the initiate plasticity. If the growing plasticity continues, then the sudden local connection of the plastic zone will cause a discontinuous stress drop, which is a mutation effect that depends on the local material degradation. The mutation refers to the sudden stress drop, which is not a gradual decreasing drop. After the peak stress, the continuous coal mass is separated into blocks or structural groups, which indicates that the geometric structure of discontinuities dominates the macroscopic behavior. The sudden failure often induces a structural stress drop.

It is important to understand the stress drop considering both the accumulated plasticity and crack connection (Kong et al. 2014; Wang et al. 2016, 2017). The generation of increasing plasticity is due partly to the local crack connection. Therefore, the stress drop exists at both the elastoplastic boundary and the failure boundary considering the mining effect. Theoretically, there are two types of solution for the continuous distribution. One is based on the Mohr-Coulomb failure criterion, which is solved by substituting the yield formula into the differential equation of stress balance (Molinda et al. 2008; Qian et al. 2003), ignoring the difference between the yield criterion and the failure criterion. The other depends on the statistical failure rule instead of the Mohr-Coulomb failure line (Airey 1974, 1977). To reduce the degree of freedom of the partial differential equations of stress equilibrium, both methods are based on a hypothesis of the predetermined relationship of the principal stresses.

However, both methods are used for continuous solutions. Recently, we have proposed a discontinuous solution by introducing the stress drop at the yield and failure lines in the statistical way (Xue et al. 2018a, b). Based on Mohr's circle, a challenge remains to describe the stress drop combined with the yield and failure lines.

Many experimental studies have focused on the brittleductile transition under different confining stresses (Papeschi et al. 2018; Niemeijer and Spiers 2005; Nygård et al.
2006). There is always a transition between the yield stress and failure stress. In coal mining, the distribution of abutment pressure is similar to the stress-strain relationship under CTC testing.

Currently, many constitutive formulas depend only on the increasing confining pressure without the unloading effect, especially no sudden stress drop. Illustrating the discontinuous phenomenon reasonably requires an unloading relationship that depends on the stress path. An effective way to create such relationship is based on the damage dependence of the accumulated plasticity, which can be determined quantitatively by considering the local crack connection. Therefore, establishing a plastic zone between the yield and failure lines based on Mohr's circle is useful for investigating how the loading and unloading stress paths differ. Furthermore, introducing a stress drop is good for observing sudden discontinuous behavior quantitatively.

\section{Materials and methods}

\subsection{Sample preparation}

The coal blocks were selected from a working face at a depth of $1000 \mathrm{~m}$ in Central China. The coal cylinders were then processed with the same diameter of $50 \mathrm{~mm}$ and a height-to-diameter ratio of $(2 \pm 0.2)$ :1. As shown in Fig. 1, an MTS815 GT Rock Test System was adopted for the uniaxial and triaxial compression tests.

\subsection{Uniaxial and triaxial compression tests}

By the uniaxial compression test, the bulk modulus and shear modulus are determined. The complete stress-strain

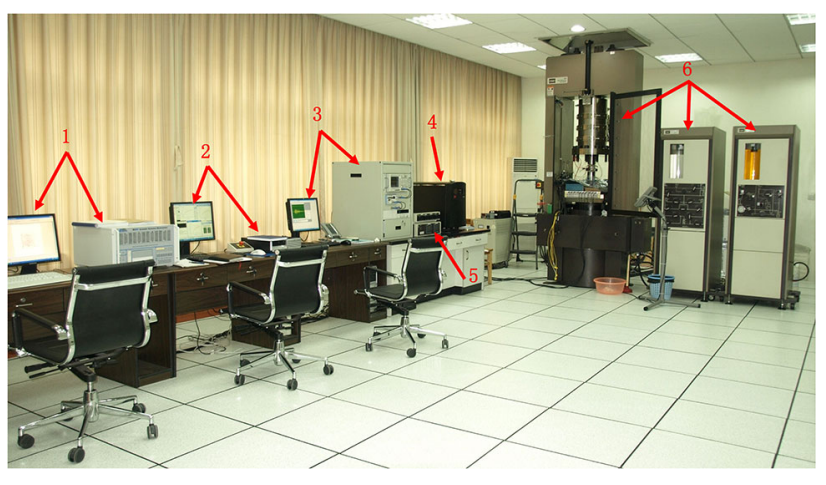

Fig. 1 MTS815 Rock Test System, which comprises six subsystems: 1-an acoustic three-dimensional positioning and collection system; 2-an MTS815 process control and acquisition system; 3-an ultrasonic excitation and acquisition system; 4-an MTS815 control center; 5-a high-temperature control system; 6-a loading system (axial, seepage, and confining pressures) 
curves of four samples are obtained, which generally include four stages, namely (1) compaction, (2) elastic deformation, (3) plastic deformation, and (4) failure. All show brittle failure with a sudden stress drop after the peak stress.

Table 1 presents the average physical and mechanical properties. Considering the coal as a homogeneous porous medium, the bulk modulus and shear modulus are calculated as 0.965 and $0.982 \mathrm{GPa}$, respectively. The wave velocity is commonly used for investigating rock integrity. For the longitudinal and shear wave velocities, the loss rates are $7.92 \%$ and $13.79 \%$, respectively. There is an obvious loss of velocity after failure, which definitely reflects the deterioration of integrity.

Bourgeois et al. (2002) proposed an elastoplastic model considering the yield and failure lines together. Here, the conventional triaxial compression (CTC) is used to determine the yield and failure lines. The confining pressure is designed as being $3.2,4,6,8,10,12,15,16,20,22.4$, and $25 \mathrm{MPa}$. After reaching the designed confining pressure at a rate of $3 \mathrm{MPa} / \mathrm{min}$, the axial force is loaded at a rate of $30 \mathrm{kN} / \mathrm{min}$ until failure.

After the peak stress, control based on lateral deformation is applied to monitor the stress drop. A series of Mohr's circles is then plotted in Fig. 2. Some remarkable studies (Labuz and Zang 2012) have shown that the Mohr strength is consistent with the Coulomb strength under a linear condition. The yield line is commonly based on the intermediate circles to define the linear relationship. However, it will cause excessive cohesion and uniaxial compressive strength (Yu 2004). Many suggestions of how to solve this issue are based on the Hoek-Brown yield criterion.

However, the stress drop is often neglected without considering the failure criteria. For brittle failure in uniaxial compression, the yield criterion is often regarded as the failure criterion because of the mirror difference of stress. However, under high confining pressure, such a distinction cannot be neglected. Generally, Mohr's circle indicates a stress state under a fixed confining pressure and its corresponding peak stress. However, that is without considering the stress drop at the elastoplastic boundary.

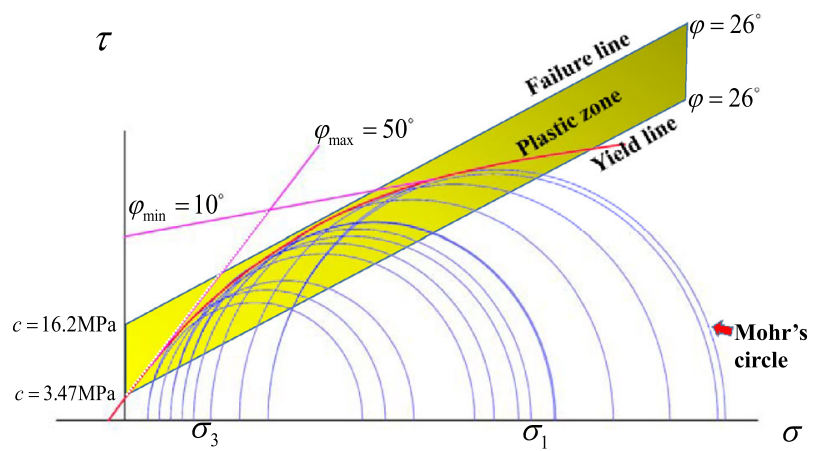

Fig. 2 Determination of two criteria for a yield line with cohesion 3.47 $\mathrm{MPa}$ and internal friction angle $26^{\circ}$ and a failure line with cohesion 16.2 $\mathrm{MPa}$ and internal friction angle $26^{\circ}$

For brittle failure, the failure line effectively illustrates the unique limited stress state as well as the yield line. However, the phenomenon of stress drop requires more attention to be paid to the sudden failure. Based on the consideration from Bourgeois et al. (2002), we propose two coupled circles considering the yield and failure states together. In this way, the yield and failure lines can be investigated simultaneously.

The yield line is determined based on circles with various confining pressures and the corresponding yield stresses. The same rule applies to the failure line, but it depends on the peak stress and its confining pressure. So, the straight line connecting all tangent points of the yield circles is defined as an elastoplastic boundary, which indicates a local connection of the crack network. Furthermore, the failure line is proposed ideally as a failure boundary, which indicates a complete connection.

In Fig. 2, the failure line is determined with a cohesion $c$ of $16.2 \mathrm{MPa}$ and an internal frictional angle $\varphi$ of $26^{\circ}$. Considering the Hoek-Brown yield criterion, a small value of cohesion, namely $3.47 \mathrm{MPa}$, is determined based on the tangent of the two smallest circles. By shifting the failure line in a parallel manner, the yield line is determined crossing the intersection point with a cohesion of 3.47 MPa.

Table 1 Physical and mechanical properties

\begin{tabular}{|c|c|c|c|c|c|c|c|}
\hline \multicolumn{4}{|c|}{ Physical and mechanical parameters } & \multicolumn{2}{|c|}{ Elastic zone } & \multicolumn{2}{|c|}{ Failure zone } \\
\hline $\begin{array}{l}\text { Density }(\mathrm{g} / \\
\left.\mathrm{cm}^{3}\right)\end{array}$ & $\begin{array}{l}\text { Compressive strength } \\
\text { (MPa) }\end{array}$ & $\begin{array}{l}\text { Bulk modulus } \\
(\mathrm{GPa})\end{array}$ & $\begin{array}{l}\text { Shear modulus } \\
(\mathrm{GPa})\end{array}$ & $\begin{array}{l}\mathrm{LWV}(\mathrm{m} / \\
\mathrm{s})\end{array}$ & $\begin{array}{l}\mathrm{SWV}(\mathrm{m} / \\
\mathrm{s})\end{array}$ & $\begin{array}{l}\mathrm{LWV}(\mathrm{m} / \\
\mathrm{s})\end{array}$ & $\begin{array}{l}\mathrm{SWV}(\mathrm{m} / \\
\mathrm{s})\end{array}$ \\
\hline 1.35 & 6.31 & 0.965 & 0.982 & 819.9 & 395.3 & 755 & 340.8 \\
\hline
\end{tabular}

$L W V$ longitudinal wave velocity, $S W V$ shear wave velocity 


\subsection{Theoretical solution for stress drop}

Unlike the material behavior determined by uniaxial and triaxial compression tests, coal mining mainly indicates an excavation behavior with typical stress redistribution on increasing axial stress and decreasing confining pressure. It often causes the coal to deteriorate, and so it shows a coupling behavior of deteriorated material and stress redistribution. The two yield and failure lines are useful for describing the unloading behavior.

For the coal working face, the damage zone is often divided into (1) the stress-relieved zone, (2) the stressconcentrated zone, and (3) the in situ stress zone. So for the redistribution of abutment pressure, the local crack connection will cause a stress drop at the elastoplastic boundary. Recently we have proposed a discontinuous solution of abutment pressure with two types of stress drop, namely (1) a discontinuous stress drop at the elastoplastic boundary and (2) a structural stress drop at the failure boundary (Xue et al. 2018a, b). The two stress drops are determined by

$\begin{cases}\hat{\sigma}=k p_{o}+\sigma_{o} & \text { at elastoplastic boundary } \\ \bar{\sigma}_{y}=k^{\prime} p_{o}+\sigma_{o}^{\prime} & \text { at failure boundary }\end{cases}$

where $\hat{\sigma}, \bar{\sigma}_{y}$ are the concentrated stresses at the elastoplastic and failure boundaries, respectively, $p_{o}$ is the in situ stress, $\sigma_{o}^{\prime}$ is the deteriorated uniaxial compressive strength $\sigma_{o}$. $k^{\prime}=\frac{1+\sin \varphi^{\prime}}{1-\sin \varphi^{\prime}}$ and $k^{\prime}$ is the deterioration of $k=\frac{1+\sin \varphi}{1-\sin \varphi}$, and $\varphi^{\prime}$ is the deteriorated internal friction angle $\varphi$.

So the yield stress is determined as

$\sigma_{y}=p^{\prime \prime} k^{\prime} \exp (x F / H)$,

where $x$ is the distance measured from the working face, $H$ is the mining height, $\quad p^{\prime \prime}=\frac{\sigma_{o}^{\prime}}{k^{\prime}-1}, \quad$ and $F=\frac{k^{\prime}-1}{\sqrt{k^{\prime}}}+\left(\frac{k^{\prime}-1}{\sqrt{k^{\prime}}}\right)^{2} \tan ^{-1} \sqrt{k^{\prime}}$. The increasing elastic stress is

$\sigma=\left(\hat{\sigma}-p_{o}\right) \exp \left(\frac{x_{b}-x}{C^{\prime}}\right)+p_{o}$,

where the exponential decay coefficient is $C^{\prime}=\left(A_{w}+p_{o} x_{b}-A_{b}\right) /\left(\hat{\sigma}-p_{o}\right)$. Here, $A_{w}$ is the area of the free zone or gob of $A_{w}=0.15 \gamma h^{2}$, where $\gamma$ and $h$ are the average weight and depth of the overlaying strata. After integration, $A_{b}=\int_{0}^{x_{b}} \sigma_{y} \mathrm{~d} x$ is $A_{b}=\frac{H}{F}\left(k^{\prime} p_{o}+\sigma_{o}^{\prime}-k^{\prime} p^{\prime \prime}\right)$.

The location of the peak stress in front of the working face is solved by

$x_{b}=\frac{H}{F} \ln \left(\frac{k^{\prime} p_{o}+\sigma_{o}^{\prime}}{k^{\prime} p^{\prime \prime}}\right)$.

Considering the linear relationship, there is the commonly known expression of $\sigma_{o}=2 c \sqrt{k}=\frac{2 c \cos \varphi}{1-\sin \varphi} \quad$ or $\quad \sigma_{o}^{\prime}=2 c^{\prime} \sqrt{k^{\prime}}=\frac{2 c^{\prime} \cos \varphi^{\prime}}{1-\sin \varphi^{\prime}}$,

where $c^{\prime}$ is the deteriorated cohesion $c$.

\section{Results}

\subsection{Difference between two stress drops}

The two groups of coal parameters determined from the yield and failure lines are substituted into Eqs. (2) and (3), and the two distributions of abutment pressure are compared in Fig. 3. Different stress peaks and stress drops definitely exist at the two boundaries. The stress concentration at the elastoplastic boundary is lower than that at the failure boundary. For the redistribution of abutment pressure, the discontinuous stress drop and structural stress drop show a clear difference.

The stress drop and other values are listed in Table 2. Based on the failure line, the discontinuous stress drop is calculated as $56 \mathrm{MPa}$, which is larger than the $29.5 \mathrm{MPa}$ at the elastoplastic boundary. However, for the structural stress drop, the trend is opposite: the structural stress drop of $32.02 \mathrm{MPa}$ at the elastoplastic boundary is much larger than the $4.55 \mathrm{MPa}$ at the failure boundary. The total stress drops for the failure and yield lines are close to each other.

After failure, the residual stress determined by the yield line is $11.88 \mathrm{MPa}$, which is lower than the $55.45 \mathrm{MPa}$ by the failure line. In addition, the corresponding elastoplastic boundary varies from 0.023 to $0.385 \mathrm{~m}$. The result determined by the yield line is more reasonable than that by the failure line. Therefore, proposing the two lines appears to be effective for investigating the stress drop.

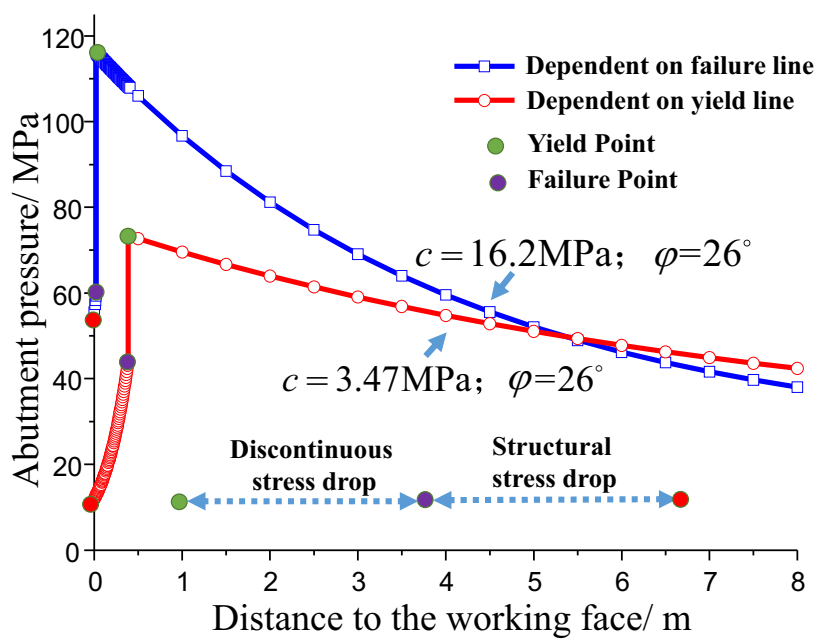

Fig. 3 Comparison of abutment pressure distribution influenced by two lines 
Table 2 Detailed results determined by yield or failure line

\begin{tabular}{|c|c|c|c|c|c|c|c|c|}
\hline \multirow{2}{*}{$\begin{array}{l}\text { Parameters } \\
\text { Different zone }\end{array}$} & \multicolumn{3}{|c|}{ Peak stress (MPa) } & \multicolumn{2}{|c|}{ Peak coefficient } & \multicolumn{3}{|l|}{ After yield } \\
\hline & $\begin{array}{l}\text { Ela } \\
\text { zone }\end{array}$ & $\begin{array}{l}\text { Pla } \\
\text { zone }\end{array}$ & $\begin{array}{l}\text { Stress } \\
\text { drop }\end{array}$ & $\begin{array}{l}\text { Ela } \\
\text { zone }\end{array}$ & $\begin{array}{l}\text { Pla } \\
\text { zone }\end{array}$ & $\begin{array}{l}\text { Residual stress } \\
(\mathrm{MPa})\end{array}$ & $\begin{array}{l}\text { Elastoplastic boundary } \\
\text { (m) }\end{array}$ & $\begin{array}{l}\text { Structural stress drop } \\
(\mathrm{MPa})\end{array}$ \\
\hline $\begin{array}{l}\text { Failure line } \\
\text { dependent }\end{array}$ & 116 & 60 & 56 & 4.64 & 2.4 & 55.45 & 0.023 & 4.55 \\
\hline $\begin{array}{l}\text { Yield line } \\
\text { dependent }\end{array}$ & 73.4 & 43.9 & 29.5 & 2.936 & 1.756 & 11.88 & 0.385 & 32.02 \\
\hline
\end{tabular}

Ela elastic, Pla plastic

\subsection{Damage-induced stress drop}

For the three mining layouts (Xie et al. 2012; Xue et al. 2013), namely non-pillar mining (NPM), top coal mining (TCM), and protective coal mining (PCM), various stress concentration of $3.00,2.00$, and 1.20 will cause different damage. Such classification is used to quantify the intensity of stress disturbance under different mining layouts.

Here, assuming the same damage of internal friction angle and cohesion, the damage is defined as

$D=\left(1-\frac{\varphi}{\hat{\varphi}}\right)$ or $\left(1-\frac{c}{\hat{c}}\right)$,

where $\hat{\varphi}, \hat{c}$ are the improved internal friction angle and cohesion, respectively, due to the coal compaction.

According to Eq. (1), $k$ and $k^{\prime}$ are used to calculate the cohesion and internal friction angle before and after deterioration. Based on the two ratios of stress concentration of 3.00 to 2.00 and 3.00 to 1.20 , for intact coal the cohesion and internal friction angle are $3.47 \mathrm{MPa}$ and $26^{\circ}$ for NPM, $2.31 \mathrm{MPa}$ and $17.33^{\circ}$ for TCM, and $1.38 \mathrm{MPa}$ and $10.4^{\circ}$ for PCM, respectively.

Here, the damage of $0,0.33,0.50,0.60$, and 0.67 is used to illustrate how it influences the stress drop. Furthermore, considering the three mining layouts, the evolution of the elastoplastic boundary and peak stress coefficient with damage is demonstrated in Fig. 4.

The elastoplastic boundary shows nonlinear growth with increasing damage in Fig. 4a. Without damage, the boundaries are determined as $0.12,0.24$, and $0.56 \mathrm{~m}$ for PCM, TCM, and NPM, respectively. When the damage is 0.67 , the boundaries increase to $6.5,6.7$, and 7.1 times more than that with no damage. The broadening boundaries in sequence from large to small are NPM, TCM, and PCM, as well as the peak stress coefficient with increasing damage. Without damage, the peak stress coefficient is calculated as $3.00,2.10$, and 1.57 , respectively. Under damage of 0.67 , the values reduce rapidly to $1.46,1.29$, and 1.17, which indicate an obvious stress drop in Fig. 4b.
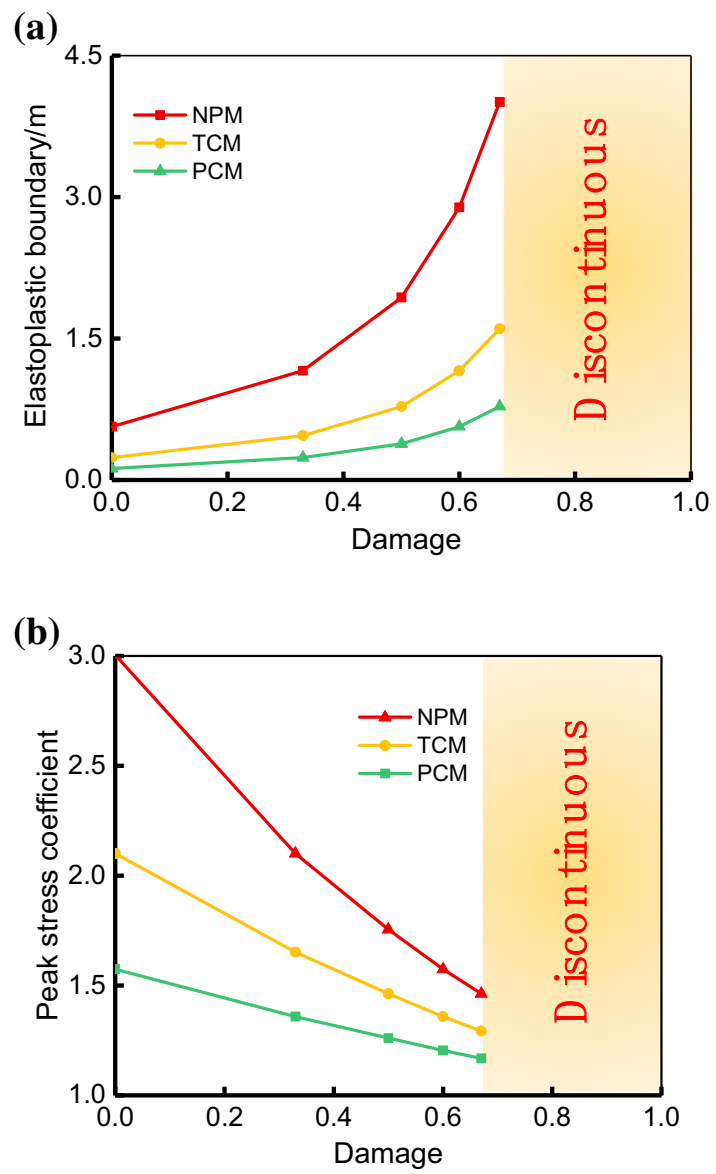

Fig. 4 Plastic zone with increasing damage of a elastoplastic boundary and $\mathbf{b}$ peak stress coefficient

Figure 5 shows the stress drop at the elastoplastic boundary and the residual stress considering various damages. In value, the stress drop increases nonlinearly with increasing damage followed by non-pillar mining (NPM), top coal mining (TCM), and protective coal mining (PCM). However, with no damage, there is no stress drop. The result is consistent with the traditional continuous distribution of abutment pressure. When the damage reaches 0.67 , the stress drop increases rapidly to 38.6, 20.2, and 10.1 MPa for NPM, TCM, and PCM, respectively. 

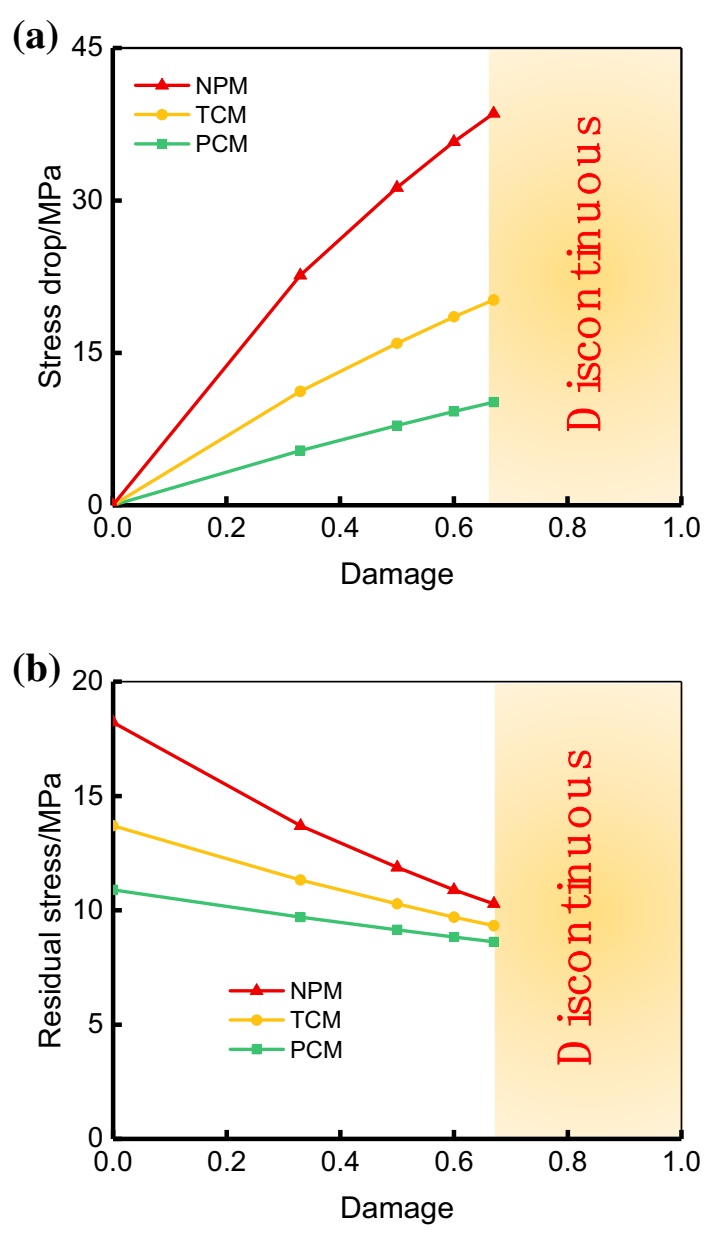

Fig. 5 Failure zone with increasing damage of a stress drop and b residual stress

Moreover, the residual stress decreases linearly with increasing damage and has the same sequence in value with stress drop of NPM, TCM, and PCM. Moreover, without damage, the residual stress is $18.2,13.7$, and $10.9 \mathrm{MPa}$, respectively, and the values are slightly larger than the uniaxial compression strength. When the damage reaches 0.67 , the residual stress is $10.3,9.3$, and $8.6 \mathrm{MPa}$, respectively, and the corresponding values are very close the uniaxial compression strength. So considering the damage effect on the stress drop is more reasonable.

By introducing the stress drop at the elastoplastic boundary, the clear comparison and discontinuous difference of abutment pressure distribution under three mining layouts show the effectiveness and necessity based on the analysis of the elastoplastic boundary, peak stress coefficient, stress drop, and residual stress.

\subsection{Stress drop sensitivity}

The yield and failure lines depend on the cohesion and internal friction angle. In coal mining, coal deterioration appears obviously with increasing deviatoric stress. Also, with increasing elastic stress, the porous coal becomes compacted with enhanced mechanical parameters. In other words, the enhancement or deterioration of mechanical parameters in coal mining depends on the stress state and damage. So the enhancement or deterioration of the bulk and shear moduli has an influence on the stress drop.

In Table 3, the influences of the bulk modulus $K$ and shear modulus $G$ are studied by designing enhanced and deteriorated parameters. The corresponding values are set as being larger or smaller by two to four times than that determined by uniaxial compression. Using the FLAC3D software, a series of numerical samples with a height of $100 \mathrm{~mm}$ and a diameter of $50 \mathrm{~mm}$ are built. In addition, the confining pressure is set as $25 \mathrm{MPa}$ considering the depth of $1000 \mathrm{~m}$, and the axial force is loaded at a rate of $0.004 \mathrm{~mm} / \mathrm{step}$.

Figure 6 shows the stress drop at the failure boundary influenced by the bulk and shear moduli. With increasing bulk modulus, the stress drop increases nonlinearly from 17.71 to $60.33 \mathrm{MPa}$. However, with increasing shear modulus, the stress drop decreases linearly from 33.31 to $31.21 \mathrm{MPa}$ with just a little change in stress value. An obvious point is around the bulk modulus of $0.965 \mathrm{GPa}$ and the shear modulus of $0.982 \mathrm{GPa}$. The deteriorated parameters have a greater influence on the stress drop than do the enhanced values. Moreover, the stress drop is more sensitive to the bulk modulus than to the shear modulus.

\section{Discussion}

\subsection{Qualitative influence on stress drop}

For convenient solution of discontinuous abutment pressure, the damage based on cohesion is assumed consistent with the internal friction angle in Eq. (6). Therefore, it is necessary to investigate the more general distribution of cohesion and internal friction angle.

Figure 7 shows the various failure lines determined by a series of the combination of cohesion and internal friction angle, and different zones are marked in three colors to distinguish those that depend on the cohesion only, the internal friction angle only, and both parameters. For constant internal friction angle, the parallel area in green color is determined for the cohesion-dependent zone. Similarly, for constant cohesion, the open red area is determined for the zone that depends on the internal friction angle. The extent of the coupling of cohesion and internal friction angle depends on the intersection area.

Here, the internal friction angle dominates the opening of the yield line, and the cohesion controls the parallel movement. In compression or tension, there is an 
Table 3 Determined parameters for numerical simulation

\begin{tabular}{lllll}
\hline Series & Bulk modulus $(\mathrm{GPa})$ & Shear modulus $(\mathrm{GPa})$ & Cohesion $(\mathrm{MPa})$ & Internal friction angle $\left({ }^{\circ}\right)$ \\
\hline 1 & $0.241,0.483,0.965,1.93,3.86$ & 0.982 & 3.47 & 26 \\
2 & 0.965 & $0.246,0.491,0.982,1.964,3.928$ & 3.47 & 26 \\
\hline
\end{tabular}

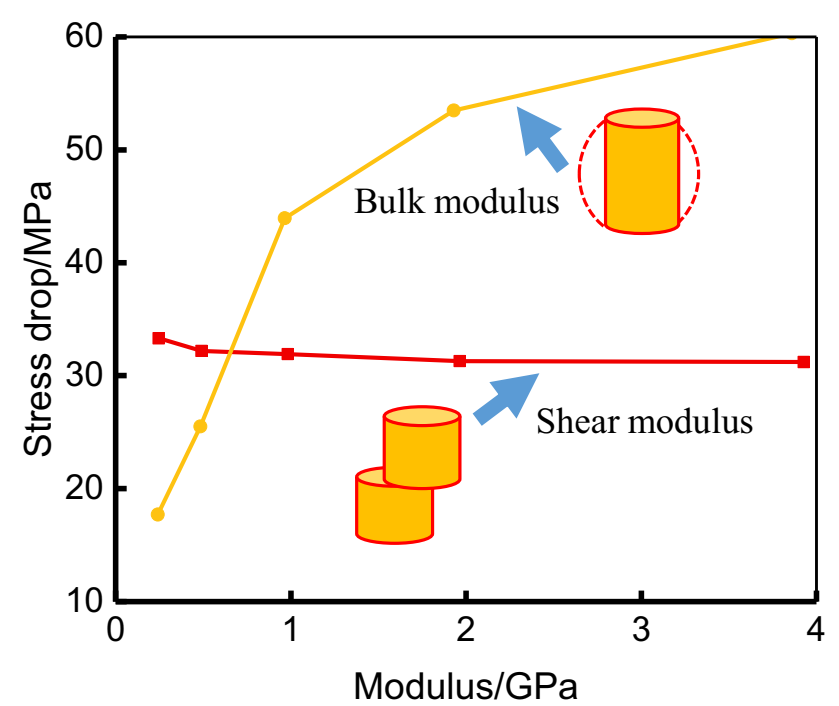

Fig. 6 Stress drop with bulk and shear moduli

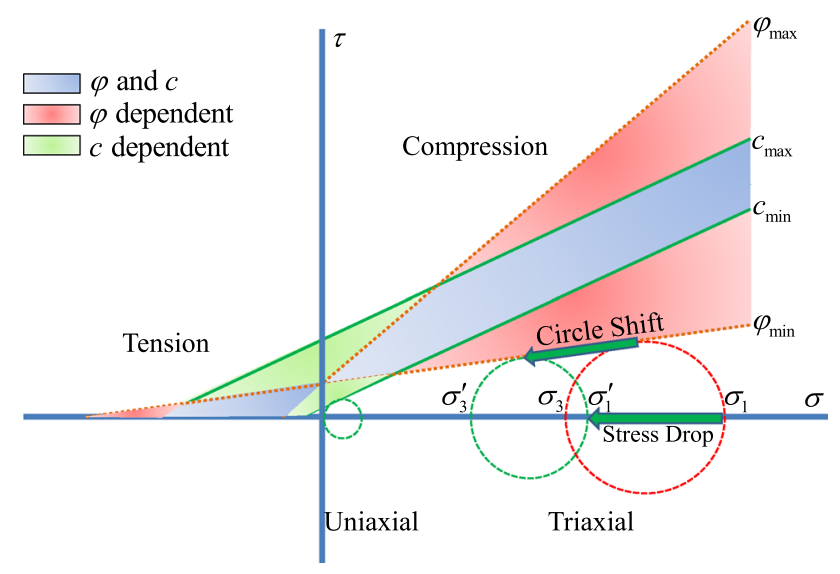

Fig. 7 Qualitative description of stress drop by cohesion and internal friction angle

interaction area marked in blue that depends on both the internal friction angle and cohesion. The red zone is the one that depends on the internal friction angle, and the green zone is the one that depends on the cohesion. When the stress state satisfies the failure line, there will be an obvious stress drop with a sudden shift of Mohr's circle.

\subsection{Quantitative influence on stress drop}

Based on a cohesion of $3.47 \mathrm{MPa}$ and an internal friction angle of $26^{\circ}$, the enhanced and deteriorated effect of cohesion is considered as being larger or smaller by two to four times, i.e. $0.87,1.74,3.47,6.94$ and $13.9 \mathrm{MPa}$. Moreover, the internal friction angle is set as $16^{\circ}, 21^{\circ}, 26^{\circ}$, $31^{\circ}$, and $36^{\circ}$ considering every $5^{\circ}$ as the step.

Figure 8 shows the stress drop with increasing cohesion and internal friction angle. For cohesion, the stress drop increases nonlinearly from 45.57 to $51.74 \mathrm{MPa}$ and then decreases to $43.5 \mathrm{MPa}$. For internal friction angle, the stress drop increases linearly from 24.6 to $74.0 \mathrm{MPa}$. The
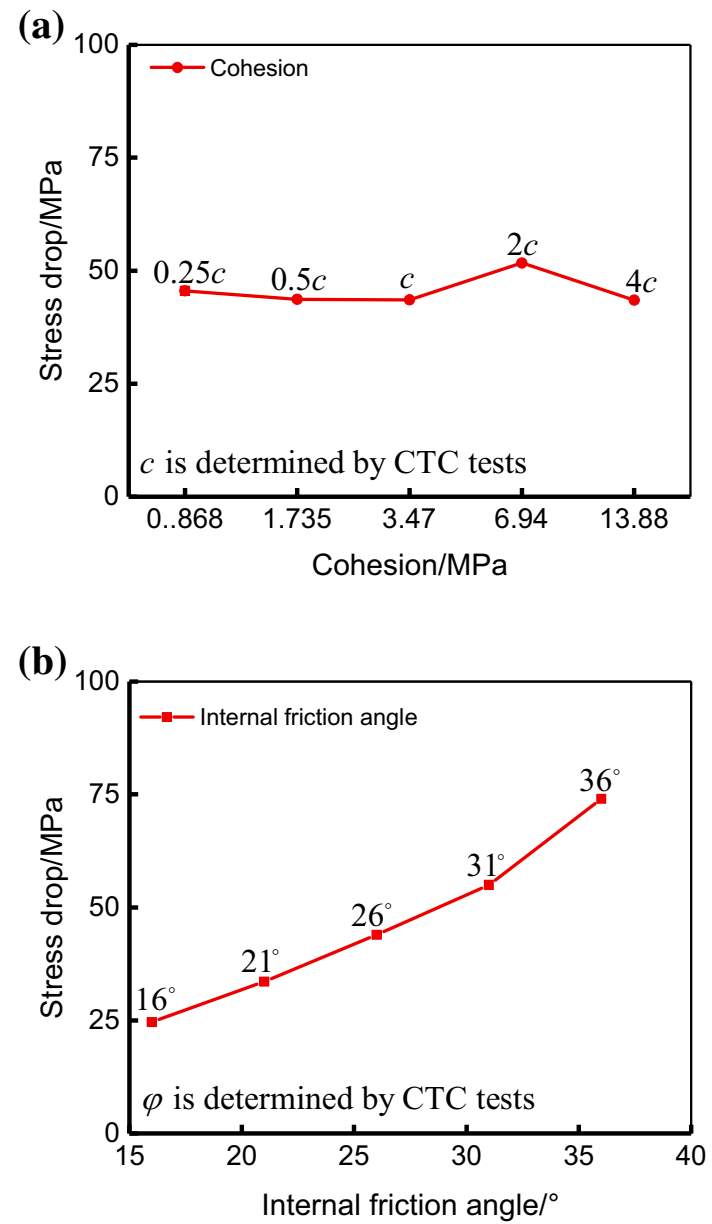

Fig. 8 Quantitative descriptions of stress drop by a cohesion and b internal friction angle 
internal friction angle has a more sensitive and positive influence on the stress drop than does the cohesion.

\subsection{Difference in stress drop}

Different parameters have different influences on the stress drop. The bulk and shear moduli dominate the elastic behavior, whereas the cohesion and internal friction angle dominate the plastic behavior. The accelerated growth of deviatoric stress induced by increasing axial stress and decreasing confining pressures will promote the coal from ductile to brittle failure.

For CTC, the brittle-ductile behavior is investigated by increasing axial stress under a fixed confining pressure. Considering every stress state, the evolution of enlarging Mohr's circle is plotted in Fig. 9. Because of the fixed confining pressure, the increasing axial stress will gradually enlarge Mohr's circle. When it passes through the yield boundary, the coal becomes ductile until failure without stress drop. The evolution includes the six states of

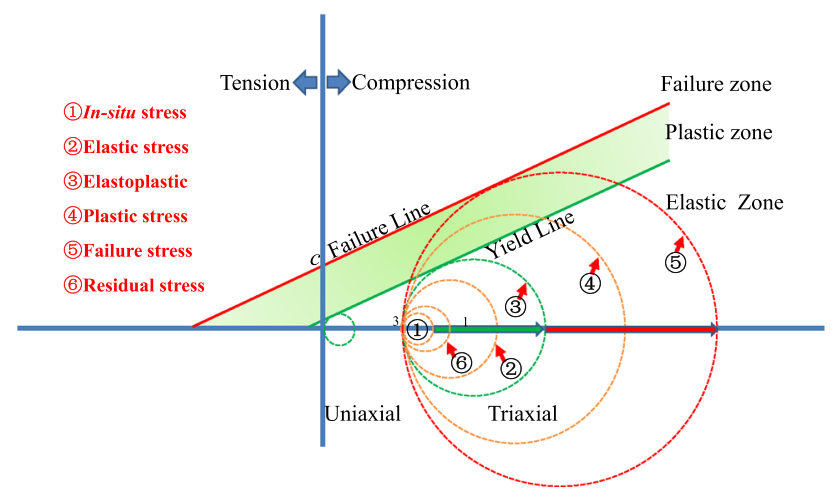

Fig. 9 Evolution of Mohr's circle considering loading effect
(1) in-situ stress, (2) elastic stress, (3) elastoplastic stress, (4) plastic stress, (5) failure stress, and (6) residual stress. In coal mining, the evolution of deviatoric stress is complex. Unlike man-made material in specific stress environments, deep coal is always under high stress. The mining behavior breaks the balance of in situ stress, and the stress redistribution will destroy integrity and deteriorate the coal. Such mining-induced stress varies from the loading stress path in the CTC test. Figure 10 illustrates the evolution of the mining-induced Mohr's circle considering the stress drop. It is more complicated, even with an opposite movement direction of Mohr's circle, than that determine by the CTC test.

Under the in-situ state, Mohr's circle is very small. When mining, the maximum principal stress (i.e., abutment pressure) increases and the minimum principal stress (i.e., confining pressure) decreases, generating a large circle. Mohr's circle then grows increasingly large with a strong adjustment of stress redistribution until it contacts the yield line. The increasing deviatoric stress causes elastic and plastic deformation, and a large Mohr's circle indicates a huge amount of stored elastic energy. When there is a locally connected plastic area, a sudden stress drop is initiated and Mohr's circle shifts suddenly along the yield line. Simultaneously, the abutment pressure changes from increasing to decreasing.

Then, the moving circle slips to the failure line. Coal is damaged more easily under low confining pressure. When the coal deteriorates from intact to the discrete state, the complete crack connection will cause a structural stress drop. However, the failure mode depends on coal resistance under residual confining pressure. There are perhaps three types of final failure. If the confining pressure decreases to zero, then the coal is under uniaxial

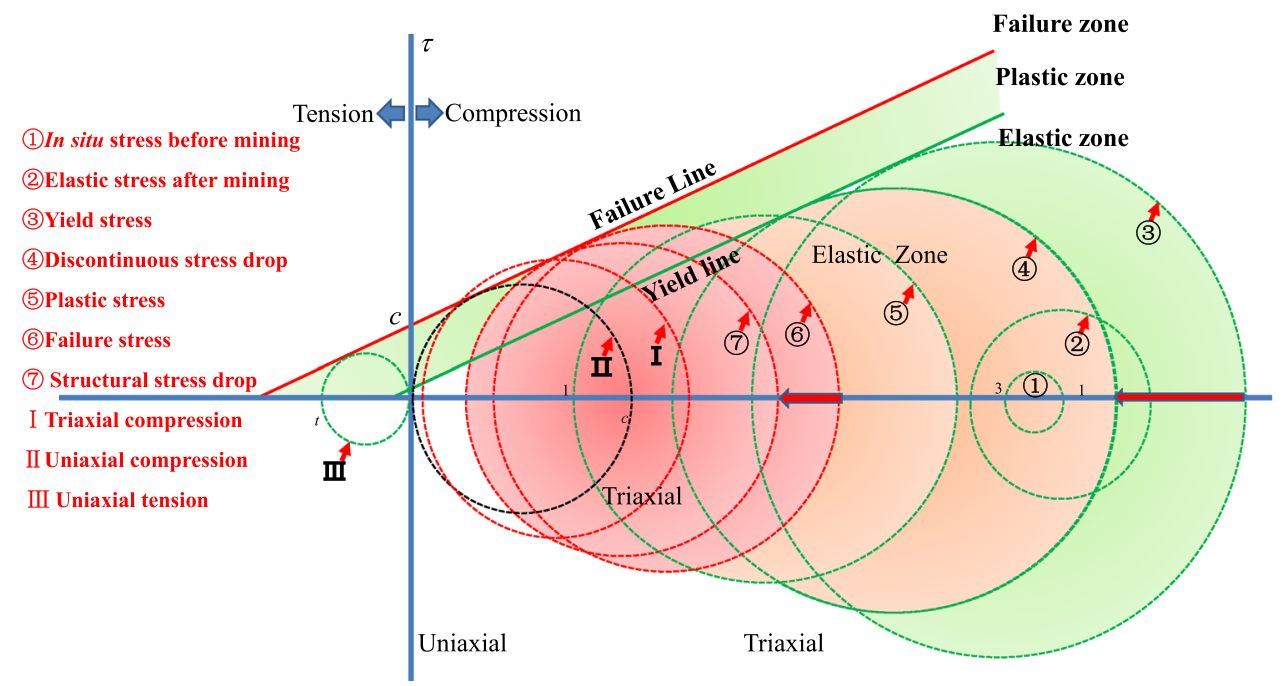

Fig. 10 Mining-induced evolution of Mohr's circle considering unloading effect 
compression. If the confining pressure is greater than zero, then the coal is under triaxial compression. Furthermore, the minimum principal stress may change from a compression state to a tension state. The evolution difference of Mohr's circle between the loading stress path by the CTC test and the unloading stress path by coal mining shows an effective description based on the stress drop.

\section{Conclusions}

In this study, the two lines of the yield and failure criteria are proposed to investigate the stress drop. Further, by the discontinuous solution of abutment pressure, the loading and unloading effect of stress is discussed considering coal damage. The main conclusions are as follows.

(1) The yield line is proposed to investigate the elastoplastic behavior. There is a plastic zone between the yield and failure lines. The yield line is effective in describing the discontinuous evolution of Mohr's circle under excavation-induced stress.

(2) There are two types of stress drop, namely a discontinuous one at the yield line and a structural one at the failure line. The former depends on the local accumulated plasticity, and the latter depends on the complete crack connection.

(3) There is an obvious opposite direction of movement of Mohr's circle considering the loading and unloading stresses. The loading stress is based on the CTC test for determining the mechanical parameters, whereas the unloading stress is based on the mining-induced pressure released for failure determination.

Funding The authors gratefully acknowledge the financial support received from the National Natural Science Foundation of China (Grant Nos. 51504257 and 51674266), the State Key Research Development Program of China (Grant No. 2016YFC0600704), the Fund of Yue Qi Outstanding Scholars (Grant No. 2018A16), and the Open Fund of the State Key Laboratory of Coal Mine Disaster Dynamics and Control at Chongqing University (Grant No. 2011DA105287-FW201604).

\section{Compliance with ethical standards}

Conflict of interest The authors declare no conflict of interest.

Open Access This article is licensed under a Creative Commons Attribution 4.0 International License, which permits use, sharing, adaptation, distribution and reproduction in any medium or format, as long as you give appropriate credit to the original author(s) and the source, provide a link to the Creative Commons licence, and indicate if changes were made. The images or other third party material in this article are included in the article's Creative Commons licence, unless indicated otherwise in a credit line to the material. If material is not included in the article's Creative Commons licence and your intended use is not permitted by statutory regulation or exceeds the permitted use, you will need to obtain permission directly from the copyright holder. To view a copy of this licence, visit http://creativecommons. org/licenses/by/4.0/.

\section{References}

Airey EM (1974) The derivation and numerical solution of equations relating to stresses round mining roadways. Doctoral dissertation, University of Surrey

Airey EM (1977) An analysis of stress round mine roadways: stresses in the failed rock, in a study of yield zones around roadways, Appendix A. Report EUR 5825e. Publications of the European Communities Luxembourg, Brussels

Allmann BP, Shearer PM (2009) Global variations of stress drop for moderate to large earthquakes. J Geophys Res Solid Earth 114:1-22

Barton CA, Zoback MD (1994) Stress perturbations associated with active faults penetrated by boreholes: possible evidence for nearcomplete stress drop and a new technique for stress magnitude measurement. J Geophys Res Solid Earth 99:9373-9390

Booth CJ (1986) Strata movement concepts and the hydrogeological impact of underground coal mining. Groundwater 24:507-515

Bourgeois F, Shao JF, Ozanam O (2002) An elastoplastic model for unsaturated rocks and concrete. Mech Res Commun 29(5):383-390

Byerlee JD (1968) Brittle-ductile transition in rocks. J Geophys Res 73:4741-4750

Evans B, Fredrich JT, Wong T (1990) The brittle-ductile transition in rocks: recent experimental and theoretical progress. Geophys Monogr Ser 56:1-20

Kong S, Cheng Y, Ren T, Liu H (2014) A sequential approach to control gas for the extraction of multi-gassy coal seams from traditional gas well drainage to mining-induced stress relief. Appl Energy 131:67-78

Labuz JF, Zang A (2012) Mohr-Coulomb failure criterion. Rock Mech Rock Eng 45:975-979

Madariaga R (1977) High-frequency radiation from crack (stress drop) models of earthquake faulting. Geophys J R Astron Soc 51:625-651

Molinda GM, Mark C, Pappas DM, Klemetti T (2008) Overview of coal mine ground control issues in the Illinois Basin. In: SME annual meeting, pp 8-17

Niemeijer AR, Spiers CJ (2005) Influence of phyllosilicates on fault strength in the brittle-ductile transition: insights from rock analogue experiments. Geol Soc Lond 245:303-327

Nygård R, Gutierrez M, Bratli RK, Høeg K (2006) Brittle-ductile transition, shear failure and leakage in shales and mudrocks. Mar Pet Geol 23:201-212

Papeschi S, Musumeci G, Mazzarini F (2018) Evolution of shear zones through the brittle-ductile transition: the Calamita Schists (Elba Island, Italy). J Struct Geol 113:100-114

Poeck E, Khademian Z, Garvey R, Ozbay U (2016) Modeling unstable rock failures in underground excavations. In: 2016 ISRM international symposium on rock mechanics and rock engineering: from the past to the future. CRC Press, ÜrgüpNevşehir, pp 505-509

Qian MG, Xu JL, Miao XX (2003) Green technique in coal mining. J China Univ Min Technol 32:343-348

Simpson C (1985) Deformation of granitic rocks across the brittleductile transition. J Struct Geol 7:503-511

Spreckels V, Wegmüller U, Strozzi T, Musiedlak J, Wichlacz HC (2001) Detection and observation of underground coal mininginduced surface deformation with differential SAR 
interferometry. In: ISPRS workshop "high resolution mapping from space", pp 227-234

Wang GF, Gong SY, Li ZL, Dou LM, Cai W, Mao Y (2016) Evolution of stress concentration and energy release before rock bursts: two case studies from Xingan coal mine, Hegang, China. Rock Mech Rock Eng 49:3393-3401

Wang L, Liu S, Cheng YP, Yin GZ, Guo PK, Mou JH (2017) The effects of magma intrusion on localized stress distribution and its implications for coal mine outburst hazards. Eng Geol 218:12-21

Wong TF, Baud P (2012) The brittle-ductile transition in porous rock: a review. J Struct Geol 44:25-53

Xie H, Zhao X, Liu J, Zhang R, Xue D (2012) Influence of different mining layouts on the mechanical properties of coal. Int J Min Sci Technol 22:749-755
Xu R, Li H, Guo C, Hou Q (2014) The mechanisms of gas generation during coal deformation: preliminary observations. Fuel 117:326-330

Xue D, Zhou H, Tang X, Zhao Y (2013) Evolution of mining induced enhancement and distribution of gas permeability in coal seam and surrounding rock. J China Coal Soc 38:930-935

Xue D, Wang J, Zhao Y, Zhou H (2018a) Quantitative determination of mining-induced discontinuous stress drop in coal. Int J Rock Mech Min 111:1-11

Xue D, Zhou H, Peng R, Wang J, Deng L, Zhao Y (2018b) Stress drop on strong disturbance of discontinuous abutment pressure. China Rock Mech Eng 37:1080-1095

Yu MH (2004) Unified strength theory and its applications. Springer, Berlin 